\title{
RAFAEL BALLESTEROS: POETA Y NARRADOR
}

\author{
ANTONIO MORENO AYORA ${ }^{1}$
}

IES Juan de la Cierva. Puente Genil (Córdoba)

\begin{abstract}
Resumen
A partir del género de la lírica, que Rafael Ballesteros cultiva desde el año 1966 con su poemario Desde dentro y desde fuera, y en el que ha alcanzado cima con el título Jacinto (editado en sucesivas versiones), el autor malagueño ha probado suerte asimismo en el género narrativo. A él pertenecen varias obras que han culminado en 2009 con la publicación de una novela extensa titulada La muerte tiene la cara azul, que debemos calificar como pentalogía por incluir en sus páginas los cinco argumentos respectivos a $E l$ peligro de la libertad, Rencor de hiena, Verás el sol, La imparcialidad del viento y Miss Damiani. El objetivo del artículo es estudiar estas novelas después de dedicar un primer epígrafe a comentar su poemario Los dominios de la emoción.
\end{abstract}

Palabras clave: lírica, narrativa, Ballesteros, Jacinto, Los dominios de la emoción, La muerte tiene la cara azul, pentalogía.

\begin{abstract}
From the lyrical genre, that Rafael Ballesteros has cultivated since 1966 and in which he reached the peak with the title Jacinto (edited in successive versions), the author from Málaga has tried his luck in the narrative genre. Thus, his last novel published, The death has the blue face, belong to this genre, and it agglutinates the arguments of The danger of the freedom, Rencor of hiena, will See the sun, The impartiality of the wind and Miss Damiani.
\end{abstract}

Key words: Lyric, narrative, Ballesteros, Jacinto, The commands of the emotion, The death has the blue face, pentalogía.

\section{OBRA LÍRICA DE RAFAEL BALLESTEROS}

La actividad literaria del malagueño Rafael Ballesteros, que durante años ha estado vinculada al género de la poesía, se inició en 1966 con su poemario Desde dentro y desde fuera, al que siguieron otros titulados Esta mano que alargo, de 1967, Las contracifras, de 1969, Turpa, de 1972, Numeraria, de 1986, o Testamenta, ya en $1992^{2}$. No

1 Correo-e: ama2530@gmail.com. Recibido: 21-12-2009; segunda versión: 18-03-2010.

2 En las últimas décadas del siglo XX, la poesía de Ballesteros había atraído ya el interés de la crítica, como lo demuestra, por ejemplo, el hecho de que su nombre figure incluido en la Antología de la poesía española contemporánea (De la ruptura del objetivismo a la dispersión moderna) que publicaron en 1991 (New York; Ottawa; Toronto: Legas) Fernando de Diego, Antonio Garrido y Francisco Ruiz Noguera. No 
obstante, la cumbre de su preocupación y de sus afanes líricos parece estar, según consenso de la crítica, en su obra Jacinto, del año 1983, que remodelada en diversas versiones se fue reeditando hasta llegar a la definitiva de 2002 publicada en Sevilla por Ediciones Alfar: Jacinto. Primera versión de la IV y última partes. Puede concluirse, sin embargo, que si en Las contracifras o en Numeraria hallábamos a un Ballesteros que desnudaba su corazón para descubrir sentimientos personales que emergían impulsados por los resortes de vivencias sociales y políticas o por la reflexión sobre el orden del mundo unido indisolublemente a la idea de número, en Jacinto es el mismo autor el que se coloca la máscara teatral para dar vida a un tipo de poesía épica revestida de clasicismo por la elección de sus personajes, insuflada de aliento filosófico por el planteamiento discursivo, y rebosante de humanidad por el entronque experiencial de las anécdotas 4 .

No hubo, pues, intervalo temporal entre la publicación de esta última obra y la que le siguió en 2003 representada en un nuevo poemario que, sin ofrecer total ruptura con lo anterior, anunciaba otro modo de concebir la escritura y de transmitir la vehemencia del sentimiento: hablamos de Los dominios de la emoción (Madrid, PreTextos), que por ser su libro de poesía más reciente comentamos en la primera parte de este breve artículo.

\subsection{Sobre "Los dominios de la emoción"}

Acertaba plenamente Rosa Romojaro cuando, en su colaboración para el Diccionario de escritores de Málaga y su provincia (Madrid, Castalia, 2002), afirmaba (pág. 94) que

Todo el universo poético de Ballesteros está en Jacinto. Sus intereses, su ideología, su concepción de la vida, de la sociedad, del arte, de la literatura, los diversos registros de su estilo, su lengua literaria en la infinidad de sus matices, su oscuridad y su claridad.

Y desde nuestro punto de vista, si se revisan las sucesivas versiones de tal obra ( $1^{\text {a }}$ de $1983,2^{\text {a }}$ de $1987,3^{\text {a }}$ de 1998 y $4^{\text {a }}$ de 2002) se llega a la conclusión de que en cada una ha tratado Rafael Ballesteros una cuestión fundamental para el hombre, y que en

obstante, según anota Antonio Aguilar en su ensayo Del paraíso a la palabra. Poetas malagueños del último medio siglo (1952-2002). Antología (Archidona, Aljibe, 2003, pág. 54, nota 8), la primera vez que se le cita en una antología es en 1967, cuando El Bardo editó Doce jóvenes poetas españoles.

3 La consideración de que estos y otros poemarios del mismo Ballesteros conforman dos etapas diferentes dentro de su producción la debemos al artículo de José María Balcells "La escritura marginal de Rafael Ballesteros", donde se estudia su obra poética teniendo como eje central su largo poema Jacinto. Véase el artículo citado en la página web con los siguientes datos: $h t t p: / / w w w . r a c o . c a t /$ index.php/Caligrama/article/view/66585/86327. Puede consultarse igualmente "Trayectoria poética de Rafael Ballesteros", artículo de Rosa Romojaro que se incluye en su propia obra Lo escrito y lo leído (Ensayos sobre literatura y crítica literaria), Barcelona, Anthropos, 2004, págs. 121-134.

4 Remitimos a nuestros artículos "La exactitud de la inteligencia. El poeta malagueño Rafael Ballesteros publica Jacinto" (en Diario Córdoba. Cuadernos del Sur, 12 de septiembre de 2002, pág. 9), y "Jacinto (Primera versión de la IV y última parte), Rafael Ballesteros, Alfar, Sevilla, 2002" (en Canente. Revista literaria, 3-4, 2002 (Málaga), págs. 457-464). 
realidad son esas mismas cuatro preocupaciones vitales las que ahora reaparecen con un planteamiento eminentemente lírico en el citado último poemario de 2003.

Es este un libro reflexivo, reconcentrado, íntimo en distintos planos y efectivamente deudor en ciertos aspectos del estilo que Ballesteros ha ido forjando en esa obra mayor y fundamental que es Jacinto. De ella conserva el gusto por la indagación (es este, por cierto, el título de un poema y el de toda la primera parte del libro) y la tendencia a formarse un conocimiento lo más exacto posible de la identidad personal: ahora no es el personaje Jacinto, sino el propio protagonista lírico, el que se pregunta repetidamente sobre quién es, representando esta razón una de las decisivamente definitorias del primero de los cuatro apartados que constituyen el poemario: “Indágame. / Entre aquello que oculto / y lo que tú supones". La otra razón, igualmente primordial, es la reflexión emocionada sobre los recuerdos que el narrador ha ido acumulando tras las variadas experiencias que le ha dejado la muerte de seres cercanos: "Ella, entonces, en la muerte, ya no / era mi madre. Sólo ella”. Y si lo que importa es la vida, la muerte se ve como agente que despersonaliza, aniquilador de la identidad, es la no vida, con lo que se establece un nuevo punto de contacto con los planteamientos filosóficos esbozados en Jacinto. Desde estos primeros versos, el lector descubre un libro intenso, contradictorio por cuanto está estructurado con un ritmo de lectura rápido (la construcción de cada verso exige pasar rápidamente al siguiente) que a la vez obliga al pensamiento a detenerse para penetrar las sugerencias, descifrar los significados y entender los mensajes acertadamente.

La experiencia y los recuerdos definen todo el poemario, que en la II parte amplía su contenido a temas de la realidad social y política, mostrando los deseos de compartir vivencias e intuiciones y rechazando los comportamientos líricos aislacionistas. En muchos de estos casos se entrevé el reflejo de enquistadas situaciones personales de las que el poeta quiere transmitir no la anécdota sino la íntima vibración lírica que aquellas le dejaron: "Yo sí. Yo cada día escribiré el recuerdo. / Mi silencio dentro de aquel silencio $[\ldots]^{\prime \prime}$.

Es evidente que cada apartado del libro posee su propio latir, como ha admitido Ballesteros en una entrevista publicada en El País con fecha de 2 de junio de 2003. El de la III parte se aviva por el amor y por la fuerza sugerente del erotismo. De sus versos emergen recuerdos y sensaciones proyectados por momentos de intimidad y de pasión, en los cuales tampoco cesa la búsqueda de la propia personalidad y del conocimiento de lo instintivo: "Yo no era realmente yo, sino el temblor / de ser el otro y más que a ti quería / lo que soñaba yo de ti y no hurgaba". Ballesteros ve el amor como una fuerza "que nos condena a nuestro exilio / y a la perseverancia de una sombra / que sí acompaña, pero que nos delata". Es decir, el amor obliga al hombre a salir de sí mismo y a buscarse en el otro ser -su sombra- que al mismo tiempo le descubre su identidad.

Nuevo latido percibimos, finalmente, en los seis poemas del último apartado, "Del desánimo y las sombras", en el que se alojan versículos más amplios que los versos precedentes. El tono familiar y directo de los mismos ("y delante poniéndome 
decía") se conecta con descubrimientos personales sobre la sociedad y con sentimientos de desolación y desaliento. No sólo se habla del protagonista sino también de otros personajes, aunque lo que aquilata el lirismo es una mezcla de estrategias de refugio y defensa que dejan entrever un anecdotario de sucesos negativos que justifican el título del apartado, el más narrativo de los cuatro y, en cierto modo, el que los aglutina. Bajo el rótulo "Al término" surgen, sin duda, los símbolos unificadores: espacio para descansar, sillas para indagar, reflexionar y disfrutar, agua para refrescar la necesaria pasión y amigos para avivar la solidaridad y compartir ${ }^{5}$. Por fin, la composición de cierre "Poema de asonancias y muerte" arrastra la sombra más perenne del hombre, su preocupación más incesante, la que ya dejó eco en los primeros poemas del libro y que ahora retoma para concluirlo: "Que todo es trasmonte hueco, / sustancia accidental. / Que tras, nada"; "Ay del hombre. Sus recuerdos se / esfuman con su vida. Sus palabras / se quedan en la tierra".

Como ha aclarado Ballesteros en la citada entrevista de El País, este libro está concebido efectivamente con una estructura cuatripartita porque su intención es reflexionar, respectivamente y a partir de las propias experiencias acumuladas, sobre la más profunda identidad del protagonista lírico ("Entonces, será así: yo estoy hecho de / otro más. Y ése, el otro, no yo [...]"); sobre sus recuerdos y vivencias conectados a la realidad social y política ("Oh, el silencio de la / noche. Yo, arriba, / arriba. De esa litera el bajo es otra celda. / ¿Quién sabe lo que un hombre solo piensa / así?"); sobre las trepidantes convulsiones íntimas del amor y del erotismo ("-Quítate las sedas de tu cuerpo, / la enagua de satén, las cintas / de tu corpiño -te gritaba- la parte / húmeda de tu algodón -y te rogaba- / pero no te quites tus sueños todavía"); y por fin sobre los sentimientos de tristeza o desaliento y de la preeminencia vital de la muerte, que no solo es sombra acuciante en la $4^{\text {a }}$ parte del poemario sino también en las que la preceden ("Ay del hombre. Sus recuerdos se / esfuman con su vida. Sus palabras / se quedan en la tierra").

Ballesteros ha dado a luz un libro emocionante y reflexivo, saturado de experiencias vitales ante todo, matizado por el intimismo y los recuerdos de situaciones políticas o sociales de los que emerge con frecuencia la preocupación fundamental del hombre, la de la muerte: "Pero no me descubras mi muerte / estando yo con vida [...]". El autor avisa, con nitidez, de que lo importante para la persona debe ser su sentimiento (por eso vive en "los dominios de la emoción") y la formulación lingüística que este necesita, ampliando así la misma indagación vital y romántica de Bécquer al decir: “Tu casa era tu corazón. Y tu reino / las palabras". Su deseo de conocimiento interior y de exploración filosófica de la existencia -de los que encontramos un ejemplo fehaciente en su obra Fernando de Rojas acostado sobre su propia mano (Málaga, 2002)- lo lleva a retener formulaciones literarias del pensamiento clásico ("Lee a Epicuro. Él sabe. Nada antes,

5 De nuevo recurrimos al libro referenciado de Antonio Aguilar, en cuya página 105 leemos que ya "los sonetos que componen Esta mano que alargo, la aportación de Rafael Ballesteros a la antología de El Bardo, están teñidos de un espíritu solidario -desde el mismo título- deudor de Blas de Otero o César Vallejo". 
nada después") y ecos de la literatura hispana que remiten precisamente a Fernando de Rojas y a Melibea, a Carriedo y a Rubén Darío.

En Los dominios de la emoción se aprecian las constantes estilísticas que han hecho de Ballesteros un poeta original, creativo hasta los mismos límites de la creación y analista continuo de las posibilidades del lenguaje ${ }^{6}$. A la fluidez del pensamiento ayudan los frecuentísimos encabalgamientos ("las olas dando, dando, contra los / esquifes") y las elipsis conceptuales ("su hijo menor, yo no lo pude"); a mantener la sorpresa y atención contribuyen tanto los arcaísmos (uno muy llamativo, vide) como la posposición pronominal ("Dame / igual como me des"), sin olvidar que estos mismos fines parece tener la traslación posicional de elementos gramaticales ("Yo daría cualquier sustancia otra"). Como ocurría en Jacinto y en otros títulos anteriores (Turpa por ejemplo), Ballesteros sigue forzando las formas lingüísticas para buscar continuamente nuevos perfiles expresivos, algo que consigue con la abrumadora frecuencia de los neologismos, que unas veces afectan a la semántica del verbo ("que manúen" ['que pongan las manos']), otras a las del adjetivo (“lújuros” ['lujuriosos’]), y otras revolucionan la complementación ("es tanmucho") o la morfología ("Bócame" ['Bésamé]). Todos estos rasgos demuestran que la escritura de Ballesteros no es un acto automático o impulsivo, es un acto de reflexión completo que alcanza al mensaje, a las ideas, y en igual medida al uso de las formas lingüísticas, en las que se observa tal grado de esencialidad, de originalidad y de creatividad que obliga a agudizar constantemente el intelecto para comprender en toda su amplitud la semiótica del poema.

Digamos que el estilo literario de Ballesteros, impresionista unas veces y narrativo otras, tiene en este libro su rasgo más sobresaliente en el uso del dialogismo adaptado a los borbotones de la experiencia íntima: “Y ¿traigo a los niños? No. No. ¿Y si recuerdan?". Muchos de los aspectos expresivos y lingüísticos, tales como la frecuencia de neologismos, los abundantes encabalgamientos, el regusto por los pronombres enclíticos, la musicalidad tenue de las rimas internas, deben ser considerados ya constantes estilísticas de Ballesteros que, provenientes de obras anteriores (aunque aquilatados y desarrollados más que nada en Jacinto), resurgen nuevamente en Los dominios de la emoción para darle al poemario el sello personal de un poeta que está decidido a bordear los límites de la creación y a forzar el lenguaje para conseguir con él un alto grado de esencialidad y de originalidad que dé a cada poema unos niveles lírico y expresivo en los cuales pese tanto la fuerza de la emoción como la capacidad del intelecto para iluminar en toda su amplitud la semiótica de lo simbolizado.

\section{LA ECLOSIÓN NARRATIVA DE RAFAEL BALLESTEROS}

Los dominios de la emoción representa, por tanto, el último libro de poesía de Rafael Ballesteros que se ha puesto en circulación. Su siguiente obra editada ha significado

6 Téngase en cuenta lo que señala Antonio Aguilar en su ensayo ya citado (pág. 105): que desde muy tempranamente "Rafael Ballesteros [...] comenzará en breve un personalísimo camino poético que va a resultar muy cercano a las vanguardias y tangencial, por tanto, a las innovaciones propias de los 70". 
un cambio de intereses en cuanto que en ella el autor ha optado por la prosa eligiendo concretamente el género narrativo. A este ha quedado vinculado, en consecuencia, con su primera novela La imparcialidad del viento (Málaga, Veramar, 2004), que únicamente significa un punto de arranque si atendemos a que en años posteriores, y ya de manera continua y sucesiva, ha ido sumando los títulos Huerto místico (Málaga, Centro Cultural de la Generación del 27, 2005), Amor de mar (Sevilla, Renacimiento, 2005), Cuentos americanos (Málaga, Ateneo de Málaga, 2006), y Los últimos días de Thomas de Quincey (Barcelona, DVD Ediciones, 2006). Pero es imprescindible advertir que esta afección al género de la novela, que parte pues del 2004, se manifestó en él sin abandonar su personal lenguaje e incluso recuperando ciertos rasgos de narratividad propios de su poesía.

Con La imparcialidad del viento mostró Rafael Ballesteros una preferencia por los argumentos de corte histórico-político, ya que en ella, a partir de la anécdota del asalto a una sucursal bancaria llevado a cabo por tres individuos integrados en un grupo anarquista, se va a relatar la problemática de los presos políticos durante el régimen franquista y hasta el momento en que este deja de operar tras las amnistía general que impone la Transición. Es por esto que Francisco Morales Lomas (en artículo publicado en la revista Papel Literario Digital de 25-8-2009, véase después nota 9) ha llegado a aludir a "la profundidad de sus ideas inmersas en procesos político-sentimentales". En ese intento narrativo se va configurando paulatinamente el tono de las relaciones de amistad que se forja entre los personajes, de entre los que descuella el carácter y el comportamiento del que conoceremos como Rancho. Desde el punto de vista argumental, hay una ligazón entre esta novela y la inmediata que a principios de 2005 publica Ballesteros en Málaga, Huerto místico: se trata del predominio de la amistad, de la humanidad y de la ternura, habida cuenta de que en este último relato el narrador -que se expresa en primera persona- es "un hombre de religión que busca la santidad más alta", lo que justifica que se centre en transmitir el aprendizaje conventual de dos novicios (Martín de Santa María y Pedro de la Caridad) que van a tener experiencias religiosas llamativas bajo las paredes del monasterio ${ }^{7}$. Entre uno y otro de los títulos hay, efectivamente, variación temática pero en el fondo late una comunidad de sentimientos y de aspiraciones que harán posible que las vivencias correspondientes vibren con un intenso lirismo y una franca humanidad en sus personajes. Antonio Garrido Moraga ha hablado 8 del "estilo de esta narración poética o poesía con estructura narrativa, texto pleno en su inmanencia, texto de profundos registros y de muy rica simbología, ni más ni menos que la del huerto"; a lo que añade después que "Leer a Ballesteros es adentrarse en la niebla nítida del amor".

A la altura del 2005, año en que se publica también Los dominios de la emoción, parecía claro que el reconocido poeta malagueño iba a dar una mayor amplitud a su creatividad orientándola de modo preferente hacia la narración, género en el que se concentra redoblando esfuerzos que fructifican ese mismo año al editarse en Sevilla

7 Véase la crítica de Moreno Ayora, A. (2005: 9).

8 Garrido Moraga, A.:(2005). 
Amor de mar, un relato distinguido con el I Premio Rincón de la Victoria y con el que su autor continuaba decidido a convencer de sus dotes de novelista. De nuevo, aunque desde otro punto de vista, aflora en esta historia el poder transformante del amor, ya que el protagonista Medrano nos introduce en su profesión de marino, con inquietante peripecia vital anclada al siglo XIX, y en su particular historia de amor vivida igualmente con riesgo y sigilo. Debe añadirse que es un acierto crear en la novela un aire de belicosidad y de intriga que al fin ha de diluirse en un poético episodio de amor trágico, el mismo que funde el sentimiento y la naturaleza mediante la evocación de esas dos palabras del título: "amor (de) mar".

Sin soslayar esa fusión de sentimiento y naturaleza pero indagando los comportamientos de una sociedad que no es la española, sino la estadounidense, surge en 2006 un conjunto de relatos titulado Cuentos americanos, que refleja el punto de vista del autor y su experiencia acerca de un grupo humano al que se ha acercado con respeto y originalidad para exponer sus valores más tradicionales, dejando siempre en sus páginas "Lo que he vivido, lo que he entrevisto y un mundo imaginario", según declaró en su día (6 de abril de 2006) al periódico Málaga hoy. Las constantes argumentales de estos seis breves relatos son la complacencia en el carácter de los personajes y el hecho de que todos ellos vivan momentos de búsqueda, de indecisión, de aprendizajes. Estos momentos de búsqueda, orlados por el dolor, la emoción y la incertidumbre vuelven a repetirse en una novela original y de estructura pretenciosa -cinco capítulos en los que cambia el narrador sin cambiar el protagonista- que se titulará Los últimos días de Thomas de Quincey. En ella se conforma un argumento de cambiante intensidad, unificado en su punto de vista narrativo, variado en la importancia con que se van alternando los personajes $\mathrm{y}$, sin embargo, redundante en el valor concedido al protagonista Thomas de Quincey, nombre real de un escritor y pensador inglés de hace dos siglos, pues su existencia transcurrió desde 1875 a 1859. De su lectura resulta indudable que es la mejor novela que Ballesteros había escrito hasta la fecha, pues es un texto loable por su verismo, su certera ambientación, su minucioso análisis biográfico y su profundidad psicológica $^{10}$.

\subsection{La temática uniformadora de "La muerte tiene la cara azul"}

Ahora bien, la novela más reciente de Ballesteros y la que nos parece más significativa de todas las que ha publicado, no solo por su extensión (que se alarga hasta las 820 páginas) sino también por su pretendida y mantenida homogeneidad temática es la que se ciñe al título de La muerte tiene la cara azul (Sevilla, RD Editores, 2009), que es un rótulo de carácter uniformador porque enmascara lo que en realidad es una

9 Con estas palabras y su correspondiente ampliación hacíamos referencia a los relatos constituyentes de Cuentos americanos según la crítica que le dedicamos también en Diario Córdoba. Cuadernos del Sur (29-6-2006, pág. 5). Afirma Campos Reina, en el prólogo que escribe para estos Cuentos americanos, que "en plena madurez y con una pujanza envidiable, Rafael Ballesteros ha desembocado en la narrativa sin abandonar sus empeños anteriores".

10 Cf. nuestro punto de vista en (2007: 162-163). Igualmente remitimos a los comentarios de F. Morales Lomas en http://moraleslomas.blogspot.com/2008/03/los-ltimos-das-de-thomas-de-quincey-de.html. 
pentalogía que viene conformada por la suma de las siguientes novelas o 'libros': El peligro de la libertad, Rencor de hiena, Verás el sol, La imparcialidad del viento (remodelada o ligeramente versionada) y Miss Damiani. Ya en una primera aproximación al significado aglutinador de la novela, el crítico Francisco Morales Lomas concretó que "11 "Las cinco novelas de La muerte tiene la cara azul están publicadas en un solo volumen y abordan el tema dilatado y fascinante de la libertad".

\section{2 "El peligro de la libertad"}

En consonancia con la cita precedente, la novela que inicia la pentalogía de $L a$ muerte tiene la cara azul es precisamente El peligro de la libertad, centrada en el personaje histórico del general Torrijos (1791-1831), del que a partir de los escasos datos históricos y biográficos que se poseen Rafael Ballesteros levanta una concienzuda historia novelada en once capítulos desde 1830 a 1845, deteniéndose momentáneamente en 1831 (año de fusilamiento del militar, capítulo V) por ser este el que resuelve, frustra y aniquila todas las aspiraciones del protagonista explicando al mismo tiempo sus apasionados afanes, tal como claramente los formula en uno de sus parlamentos: "Santa Olalla, siempre hay tiempo cuando se trata de luchar por la patria y por la libertad" (pág. 22). Este es el planteamiento temático de todo el texto, recordar el pronunciamiento de Torrijos en defensa de la libertad y en espera de reinstaurar la Constitución de 1812.

Estamos ante una narración apegada al léxico marinero, transcrito siempre con exacta propiedad -por momentos uno recuerda a Amor de mar-, con una prosa mimada y tranquila, además de llamativa por su detallismo en la puesta en situación de las escenas y de las descripciones ${ }^{12}$. Con ágiles y concisos diálogos, el narrador gusta de dejar la expresión a los personajes más sencillos para que analicen las vivencias y hagan avanzar el argumento, que poco a poco juega con la curiosidad y el suspense. De entre todos, es Miguel Laín el personaje que se alza al nivel del protagonista y acaba siendo símbolo de la lealtad y la valentía, y todo ello en contraste con las repetidas muestras de traición que van jalonando los planes de Torrijos. Y así, aunque el capítulo V es central, topamos con un argumento que se continúa hacia delante para alcanzar a los años de 1843-1845, pero que a su vez retrocede cronológicamente (capítulos VIII-IX-X) para perfilar ciertos pormenores que enriquecen la trama y posibilitan la expectación de los lectores. Estos, siguiendo el ritmo reflexivo, emotivo y a ratos angustioso de la acción, son conducidos por escenarios de la costa malagueña, de algunas poblaciones del interior de la provincia (Antequera) o de la propia Málaga, de Córdoba (Rute) o de la capital Madrid (de la que se hace una descripción de su ambientación decimonónica).

11 Así comienza su reseña sobre "La muerte tiene la cara azul de Rafael Ballesteros", en www.papel-literario.com, de 25-8-2009.

12 Por añadidura, resulta curioso que el poema "Andando sobre el mar" -que Antonio Aguilar transcribe en su libro Del paraíso a la palabra. Poetas malagueños del último medio siglo (1952-2002). Antología (véase págs. 183-184) - sea igualmente de ambientación marinera y conecte así con el tono narrativo que caracteriza a esta novela sobre Torrijos. 
Tras los momentos culminantes y de mayor emoción y sufrimiento, la historia se precipita -sin traicionar la realidad- hacia el desencanto y el fracaso, dos experiencias evocadas de este modo al final del capítulo VIII y por tanto concluyentes del argumento:

A veces los sueños mejores de los hombres se desvanecen y las palabras más hermosas se ahuecan. Los sentimientos más altos se hacen humo, enferman las pasiones más intensas y se hace el mundo un esqueleto de sí mismo (pág. 118).

\section{3 "Rencor de hiena"}

Es el siguiente título Rencor de hiena, que se abre con una breve pero intensa reflexión sobre el miedo y la muerte -puede decirse que no se nota el cambio entre esta y la novela anterior-, el que enseguida permite presentar el comienzo de unos hechos que trasladan al lector al mismo día del levantamiento militar del general Franco, vivido asimismo en un pueblo de la costa oriental malagueña y en los alrededores inmediatos: “[...] no le diré que vuelvo al pueblo, le diré que marcho hacia Macharaviaya, porque por arriba de Benaque están los compañeros" (pág. 197). Aparece primero un narrador cuyo cometido es enmarcar y hacer progresar el argumento y en seguida otro, parcial y subjetivo, que representa el punto de vista de la vivencia republicana y que por ello narra en primera persona (correspondiente al "yo" de El Zagal, que dice: “Aquí en los papeles cuento nuestra historia, Lita"). Lo cierto es que uno y otro de los narradores se van alternando y apoyando, con lo cual el segundo casi siempre amplía o refuerza la narración del primero. A veces ni siquiera se nota la transición de ambos puntos de vista, excepto por la marca del tipo de letra que los individualiza (redonda o cursiva).

La acción se desarrolla deteniéndose unas veces en la tragedia colectiva, que en buena parte simboliza el grito de “¡Arriba España!” al que se vinculan personajes como el falangista Urdiales, Nevot o Aguayo, y otras veces en la tragedia personal que llega a comprenderse por la reflexión y el análisis de las emociones que surgen de personajes como Bernabé o El Zagal, cuya proclama vivencial será la de “¡Viva la República!". Determinados parlamentos (de la página 168, por ejemplo: “El que carece de ideología, ni tiene cabeza ni tiene corazón”; “¿Quién puede esperar de él que no se convierta en un traidor?") no solo son completamente congruentes con esta historia sino que pueden anudarse igualmente con la precedente de Torrijos, configurando así una unidad de contenido que justifica el marco común cuya valoración quiere ser $L a$ muerte tiene la cara azul ${ }^{13}$.

Rencor de hiena es una novela espeluznante, trágica, emotiva, de la que emergen en aluvión sentimientos como el coraje, la ira, la frivolidad, la ternura, la piedad o la desesperación, los mismos que podemos comprobar en citas como estas: "No se nos permite vivir. Desaparecer es lo único que se nos permite. Nuestra culpa es existir"

13 En alguna ocasión se explicitan llamadas internas que retroalimentan la relación sugerida: " [...] a la busca, entre las vidas de hombres valerosos, Torrijos, Robert Boyd, de algún espacio, por pequeño que fuera, donde guarecerse este pobre egoísta y cobarde” (pág. 252). 
(pág. 199); “Y aquí ya no hay piedad ni lástima. Una y otra se acabaron hace tiempo. ¡Se acabaron!" (pág. 234).

\section{4 "Verás el sol"}

Son 310 páginas las que alojan las duras vivencias de Rencor de hiena, que no van a ser sustituidas por otras mejores ni más apacibles, ya que la siguiente novela de la pentalogía va a ser Verás el sol, que parte de la acogida que, en secreto, da "la Sota" a el "Seco" (alias de Antonio Pérez Bermúdez) en una barriada malagueña cuando este junto con otros camaradas está preparando la resistencia urbana antifranquista conocida como guerrilla. He aquí otras 188 páginas repletas de personajes (además delos mencionados, la "Mora", “Tita", "Pasmao", "Terrizo", “Faldero", "Pinto", "Reverte”, "Pronto, “Montiel"...) que a través de diálogos cortos y frecuentes traslucen la rapidez de las acciones que se proyectan o ejecutan. El lector se encuentra nuevamente con una trama secundaria que estructura el argumento con un doble narrador según tome la palabra el que alude a la historia colectiva o el que expone la historia personal, el "Seco", a su vez integrante de la peripecia colectiva. Esta doble trama va indicada tipográficamente, otra vez, mediante la utilización de la cursiva.

En el contexto de la sociedad de la época, el grupo de personajes citados pretenden "ser la vanguardia de este gran ejército de la libertad. Somos revolucionarios. No somos bandoleros", según apreciación de la página 359. Y por ello, la novela atiende fundamentalmente a la organización y funcionamiento de la guerrilla, reviviendo sus inseguridades, sus miedos, sus convencimientos y su confusión de ideas, sus conexiones y desconexiones...

\section{5 "La imparcialidad del viento"}

La novela que Ballesteros publicó en 2004, su primera novela, La imparcialidad el viento, queda integrada en la pentalogía en cuarta posición, ya que es la que le corresponde según la línea cronológica de los hechos históricos. De ella hemos adelantado ya -teniendo en cuenta ahora que Ballesteros ha vuelto a versionar o revisar su argumento con mínimas aportaciones- que transcurre reflejando las relaciones de camaradería que se establecen entre un grupo de anarquistas que, tras cometer el asalto de un banco, quedan presos en la Cárcel Modelo de Barcelona durante el último periodo del régimen franquista y cuando se ve inminente la Transición.

Como característica del relato debe destacarse el recurso basado en el cambio de voces, que permite intercambiar las intervenciones del narrador (de sintaxis escueta, nominal, con ausencia de preposiciones o nexos) y las de la primera y segunda personas narrativas, cuyo vocabulario aparece necesaria y oportunamente moteado de términos jergales y a veces de localismos expresivos propios del habla andaluza ("Ustedes os vais a otro, ¿no?"). Se trata de una narración en la que son comprensibles los saltos del presente al pasado, y por lo mismo la mezcla de episodios infantiles con otros pertenecientes a la cotidianidad carcelaria. Con todo, el tipo de texto predominante 
es el dialogístico, rasgo por el que esta novela evoca el carácter dialéctico que operaba en la obra Jacinto -la redacción de una y otra estaban muy próximas-, convirtiéndose además en la razón por la que el personaje Zarra (igual que ocurriera con otros de la citada obra) es el que inquiere y fuerza continuamente a la reflexión.

La imparcialidad del viento no es, por cuanto antecede, novela de un protagonista, sino de un coro de protagonistas que viven situaciones límite y recuerdan cuanto han vivido antes de ser encarcelados. Rancho y sus numerosos amigos (Ruzafa, Rosich, Pedrosimón...) son seres que necesitan liberarse del peso de sus amargas historias, que han hecho de ellas la razón de sus esfuerzos y de su resistencia política, y que al fin las comparten porque son el salvoconducto de su sentido de la amistad y la prueba de su limpia intención (sin duda, el capítulo 10 es buena muestra de cuanto comentamos). Aunque con frecuentes rasgos de la novela policiaca y sentimental, puede decirse que esta es una novela de pensamiento más que de acción, pues en la obra la palabra ocupa el lugar de los hechos.

Este cuarto texto de Ballesteros no diverge significativamente de los anteriores, por cuanto continúa centrado en el anhelo colectivo de libertad y en las amargas experiencias del dolor y delas tragedias humanas. Sin duda alguna, la novela en conjunto simboliza la defensa de los valores humanos y cívicos: la amistad, la solidaridad ("Lo colectivo siempre es lo más”), el arrepentimiento y la búsqueda del bien (“Yo, yo no quisiera odiar más"), el convencimiento de la identidad del grupo ("En lo nuestro no se ingresa, se es"), el peso de la ilusión y de la nostalgia, y en fin, la presencia de los ideales en contraste con numerosas anécdotas de corte tremendista o escatológico.

\section{6 "Miss Damiani"}

Quien inicia la narración de este nuevo argumento titulado Miss Damiani es Cetme, el personaje con el que en su última sección ("15. Volver a devolver") se ha cerrado el título precedente La imparcialidad del viento. En realidad, estas dos novelas se complementan y Miss Damiani parece representar una segunda versión, un diferente punto de vista con el que poder referirse a personajes ya conocidos, como Rancho, Bandolé o Cetme, que ahora, con este nuevo enfoque, se relacionan con otros que el lector poco a poco irá conociendo. Quien cuenta la historia es, precisamente, Cetme, que la inicia retrotrayéndose en el tiempo con la información: “Detuvieron a Bandolé mientras dormía con la facilidad de quien agarra a un conejillo en su nasa". Cetme habla de sí mismo, residente en Mataró, y de sus primeros atracos con la banda en la que se integra (" ¿Y quieres empezar, no?"; “¿Y estás dispuesto?") para conseguir dinero con el que sufragar la resistencia anarquista que operaba a mediados de 1970. A la sazón, y según el punto cronológico de los acontecimientos narrados, Rancho y Bandolé -que están en la cárcel- traicionaron a Cetme, que por esta razón se esconde de la policía ("Llevo aquí encerrado ciento cincuenta y tres días", pág. 682) y por el mismo motivo desea una amnistía para que Rancho pueda quedar en libertad y así 
vengarse de él ${ }^{14}$. Este deseo incesante de venganza es el que mantiene su existencia, según confiesa en página 804: “Mataré a Rancho y con él acabaré con una obsesión”.

Cetme, que en los primeros capítulos (1 al 4) sitúa el relato en su juventud asaltando bancos y viviendo en clandestinidad, da un giro de pronto a la narración (capítulos 5, 6 y 7) para evocar su infancia en Andalucía, en un pueblo de la vega de Antequera, y recordar al unísono episodios de aquella niñez (verdeo en los olivares, escenas de pesca...) o algo posteriores (como su milicia en el Pirineo). Es por esta mezcla de sensaciones y sentimientos por lo que vemos que la narración va dando saltos temporales hacia adelante (momento presente) o hacia atrás, reconcentrándose con ternura en la evocación de anécdotas de su infancia a pesar de que ya desde entonces notaba el "odio, desprecio y violencia que siento en mis adentros" (pág. 690). Y esta desazón que le venía de lejos aumentó, por supuesto, a partir del momento en que tuvo que emigrar del pueblo con su familia para recalar en Mataró. Se explica de este modo que el protagonista aparezca como un desarraigado que va a tener pocos momentos de felicidad. Ese desarraigo es el que refleja al comentar que en la ciudad "hasta los vencejos y los golondrinos van diciendo qué hago por aquí, de dónde he venido yo y a dónde voy a ir. El mundo entero cambia. No sabe de verdad cuál es su sitio" (pág. 752); y el mismo asunto reaparece, por ejemplo, al referirse a "[...] aquellas mujeres desvencijadas y sin patria" (pág. 766).

Para Cetme, la felicidad es un estado al que sólo ha accedido gracias a su hermana, Miss Damiani -por cierto, el nombre con el que actúa en un espectáculo de magia-, que fue la única con la que durante un tiempo pudo ser feliz y dichoso ("Pocas veces había estado yo tan contento”, pág. 737; “Corazón, que duermas bien”, pág. 776), y a su vecina Tona que conocerá más tarde y con la que vivirá nuevos momentos de intensa pasión amorosa. En buena medida puede decirse que esta historia tiene como dos tempos, dos ritmos, uno al principio (cuando Cetme se integra en la banda de atracadores) y otro después (cuando de niño emigra con sus padres y hermana a Mataró, dominado por la ternura de su hermana "Miss Damiani"). Sin embargo, la existencia como adulto -que corresponde al momento narrativo presente- está impulsada sólo por dos fuerzas, la de la ternura que siente por Tona y la del rencor vengativo que experimenta por Rancho: “En el mismo corazón, dos sitios que no se comunican, que no se ven" (pág. 743).

Es esta la última novela de la pentalogía, pero sus rasgos estilísticos concuerdan con los trazados para las demás. En una y en otras es marca destacada la originalidad de la prosa dialogística, con la fluidez, rapidez y esencialidad que caracteriza a los turnos de palabra. Con frecuencia encontramos emocionados párrafos, largos discursos que van surgiendo con el desorden, las repeticiones y el fluir del pensamiento, vocablos del lenguaje jergal y otros completamente cercanos al neologismo ('andoteando', 'ronrales', 'agolpo', 'derrumbos'...), otros también recalcados para intensificar la acción o la cualidad ("de vez en cuando la acariciaba, suave, suave"). Vinculadas con

14 Recuérdese que esa venganza, el asesinato de Rancho, es el acontecimiento relatado en la última página de La imparcialidad del viento: "Detrás oye un ruido, después una voz: / - Rancho... Rancho. / Cuando se va a volver, Cetme le pega un tiro en la nuca" (pág. 649). 
mayor o menor consistencia las cinco historias, puede decirse que en ellas ronda un personaje que responde a un plan trazado con unanimidad, a un proyecto que quizá resuma mejor que ninguna otra calificación aquella que se expone en la págian 206: "Aquel que defendió que la idea está por encima del miedo y que lo que se sueña tiene más fuerza que la misma vida".

\section{CONCLUSIÓN}

El lector habrá entendido que en este breve trabajo únicamente hemos aspirado a tratar la obra de creación de Ballesteros, pues no debe olvidarse que a lo largo de su trayectoria como escritor se ha dedicado también a la crítica, con estudios centrados en autores como Gabino Alejandro Carriedo o Dámaso Alonso, o con antologías de otros para difundir la obra de Ricardo Molina, de Vicente Núñez o de Pérez Estrada, habiendo contribuido asimismo a la edición de poetas de la talla de José Moreno Villa (el caso de su estudio de autoría compartida sobre Jacinta la pelirroja, Castalia, 2000) o, mucho más recientemente, en 2006, de Muñoz Rojas, del que junto con Francisco Ruiz Noguera y Julio Neira ha recopilado en Cátedra sus Textos poéticos (1929-2005). Siendo así, no puede obviarse que Rafael Ballesteros, en una misma entrevista ${ }^{15}$, ha afirmado que "he creído que la poesía es un reducto de la intensidad, de la creación, de la personalidad, la emoción y no especialmente de la política"; que

desde el primer momento creí que este mundo consistía en creación, novedad, hacer del lenguaje un uso específico y controlado, en donde cabe la sorpresa, la ironía. El poema es una zona donde caben muchas cosas;

y que (según añade además) poesía y novela

Son dos cosas completamente diferentes, dos ritmos, necesidades expresivas, dos lenguas. Crear un personaje y guiarlo por acontecimientos y relacionarlo con otros personajes es totalmente diferente al fogonazo, a la luz que es la poesía verdadera.

Tales aseveraciones constatan que, se trate de uno u otro género, estamos ante un escritor consciente de su oficio, de sus posibilidades y alternativas, de su razón de ser para el arte.

En el caso de los cinco títulos constituyentes de La muerte tiene la cara azul, como se ha apuntado, debe destacarse la posibilidad de relacionar unas historias con otras, ya que el hecho de concatenar actitudes y comportamientos éticos en argumentos diferentes demuestra que Ballesteros concibe su obra como un texto total, único, y que esto permite traspasar y trasvasar palabras, símbolos, alusiones de unos contextos a otros. La hondura que Rafael Ballesteros consigue en cada una de estas cinco historias hace que pensemos que aquellas palabras de El Zagal (en la página 260) "Cuando escribo... Lo que hago es buscar más realidad. La verdadera", son aplicables a cualquiera de ellas y que, en el fondo, están aludiendo tanto a la pretensión como al compromiso que el autor mantiene vivo en todo su proceso de creación. Y lo curioso es que las concordancias temático-estilísticas no solo se observan entre estos cinco títulos de $\mathrm{La}$

15 “Entrevista con Rafael Ballesteros, por Sergio Ruiz", Liberlect, 8 (22 de diciembre de 2.003), revista de publicación electrónica en http://www.bestcom.org/liberlect/entrevista-004.html. 
muerte tiene la cara azul, sino que desde textos lejanos -en verso o en prosa- avanzan entrecruzándose, remitiéndose, repitiéndose o transformándose hasta reaparecer de nuevo en La muerte tiene la cara azul, una novela grandiosa, extensa, coherente con ella misma y con la totalidad del mundo literario del autor. Es evidente que son estos méritos intrínsecos los que han propiciado que la Asociación Andaluza de Escritores y Críticos Literarios (Críticos del Sur) haya concedido a novela tan original el 'XVI Premio Andalucía de la Critica. Modalidad Narrativa', cuyo jurado la valoró insistiendo en

la capacidad de acercarse con autenticidad al mundo de sus personajes, argumentando su visión con un lenguaje preciso, cargado de humanidad y con un basamento lingüístico que resalta los espléndidos diálogos y sus silencios ${ }^{16}$.

\section{BIBLIOGRAFÍA}

Moreno Ayora, A. (2005): “Ternura y belleza”, Diario Córdoba. Cuadernos del Sur, 7 de abril, 9.

Moreno Ayora, R. ([2006]2007): El Maquinista de la Generación, Segunda época, Número 13, febrero 162-163, “La dolorosa incertidumbre de un intelectual romántico. Rafael Ballesteros. Los últimos días de Thomas de Quincey. Barcelona, DVD Ediciones, 2006.

Garrido Moraga, A.: (2005) “Hortus”, Diario Córdoba. Cuadernos del Sur, 10 de marzo, pág. de contraportada.

16 En www.aaec.es/index.php?option=com_content\&view=article\&id=154:ganadores-del-xvi-premio-andalucia-de-la-critica\&catid=2:noticiasgenerales\&Itemid $=8$ 